\title{
INCREASED PRESERVATION OF SLICED MOZZARELLA CHEESE BY ANTIMICROBIAL SACHET INCORPORATED WITH ALLYL ISOTHIOCYANATE
}

\author{
Ana Clarissa dos Santos Pires ${ }^{1}$, Nilda de Fátima Ferreira Soares* ${ }^{1}$, Nélio José de Andrade ${ }^{1}$, Luis Henrique \\ Mendes da Silva², Geany Peruch Camilloto, Patrícia Campos Bernardes ${ }^{1}$
}

\author{
${ }^{1}$ Departamento de Tecnologia de Alimentos, Universidade Federal de Viçosa, Viçosa, MG, Brasil; ${ }^{2}$ Departamento de \\ Química, Universidade Federal de Viçosa, Viçosa, MG, Brasil.
}

Submitted: March 25, 2008; Returned to authors for corrections: June 29, 2008; Approved: July 27, 2009.

\begin{abstract}
There is an increasing tendency to add natural antimicrobials of plant origin into food. The objective of this work was to develop a microbial sachet incorporated with allyl isothiocyanate (AIT), a volatile compound of plant origin, and to test its efficiency against growth of yeasts and molds, Staphylococcus sp. and psychrotrophic bacteria on sliced mozzarella cheese. Another objective was to quantify the concentration of AIT in the headspace of cheese packaging. A reduction of $3.6 \log$ cycles was observed in yeasts and molds counts in the mozzarella packed with the antimicrobial sachet over 15-day storage time. The sachet also showed an antibacterial effect on Staphylococcus sp., reducing 2.4 log cycles after 12-day storage. Psychrotrophic bacteria species were the most resistant to the antimicrobial action. The highest concentration of AIT $\left(0.08 \mu \mathrm{g} \cdot \mathrm{mL}^{-1}\right)$ inside the active packaging system was observed at the 6 day of storage at $12{ }^{\circ} \mathrm{C} \pm 2{ }^{\circ} \mathrm{C}$. At the end of the storage time, AIT-concentration decreased to only $10 \%$ of the initial concentration. Active packaging containing antimicrobial sachet has a potential use for sliced mozzarella, with molds and yeasts being the most sensitive to the antimicrobial effects.
\end{abstract}

Key words: antimicrobial sachet, Mozzarella cheese, food protection, allyl isothiocyanate

\section{INTRODUCTION}

Antimicrobial packaging can eliminate or inhibit the growth of spoilage and pathogenic microorganisms. The basic principle of this type of packaging is to be added of a microbiological barrier besides the physical barriers to oxygen and moisture (6). It has been suggested that antimicrobial agents could be incorporated into food packaging systems to create an environment which will maintain their activity during food storage (14). According to
Santiago-Silva et al. (19), some of the antimicrobial system includes the addition of sachets containing volatile antimicrobial agents into the packages, application of edible coatings with the antimicrobial component, and the incorporation of antimicrobial agents directly to the package material.

Several studies have shown the efficiency and applicability of antimicrobial packaging, including those incorporated with natural antimicrobials. In the last 20 years,

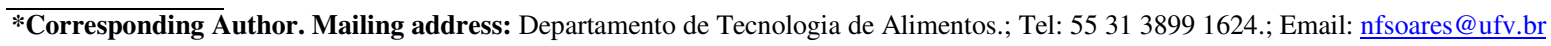


hundreds of laboratories studies have shown microbial activity of natural compounds against spoilage and pathogenic microorganisms (18).

The addition of natural antimicrobials of plant origin into foods is an increasing practice. Natural extracts and essential oils have long been utilized to extend shelf life and the sensory quality of foods (6).

Some plants, their extracts or active principles have shown antimicrobial activity in laboratory studies. Spices and herbs have different levels of biological activity; however, their effectiveness against microorganisms occurs at very high concentrations (16). On the other hand, studies have shown that some antimicrobials of plant origin are capable of inhibiting a variety of pathogens, even at low concentrations (5).

Studies show the efficiency of volatile antimicrobials against several microorganisms in a culture medium. Nielsen and Rios (15) studied the effect of six different essential oils on six types of molds in Czapek agar and observed that only mustard oil was capable of inhibiting the growth of all the microorganisms tested, including Aspergillus flavus, during seven days of incubation.

Other works have shown the efficiency of these antimicrobials of plant origin against some microorganisms in foods. Mustard oil at a concentration of $20 \%$ was effective in reducing to non-detectable levels of Escherichia coli O157:H7 after three days of storage at $4{ }^{\circ} \mathrm{C}(12)$. The use of a packaging system containing antimicrobials of volatile plant origin reduced $3 \log$ cycles in E. coli $\mathrm{O} 157: \mathrm{H} 7$ count in ground beef stored at $-18{ }^{\circ} \mathrm{C}$ (13). Allyl isothiocyanate was also effective against E. coli $\mathrm{O} 157: \mathrm{H} 7$ present in chopped beef (4).

Allyl isothiocyanate in cooked rice packed in high gas barrier packaging material was efficient in reducing $3 \mathrm{log}$ cycles of total mesophilic aerobic microorganisms after 12 hour storage at $25{ }^{\circ} \mathrm{C}(8)$. Delaquis et al. (5) observed that horseradish essential oil presented antibacterial action mainly against Pseudomonas sp. and enteric bacteria, while acid lactic bacteria were little affected.
According to Delaquis et al. (5), volatile antimicrobials are more effective when used in closed atmosphere systems that would allow volatilization of the compound and its permanence inside the packaging. Thus, the use of packaging with a lower rate of permeability to gases is recommended.

Cheese is a type of food frequently involved in outbreaks of foodborne bacterial diseases (3). Consuming refrigerated sliced food is a common Brazilian habit. The product may be contaminated during slicing if the hygiene conditions of the equipment surfaces are inadequate. One of the major risk factors in the transmission of diseases by food is crosscontamination between food and food contact surfaces (9).

Within this context, this work aimed to develop a sachet containing a volatile antimicrobial of mustard plant origin, to evaluate its antimicrobial efficiency against yeasts and molds, Staphylococcus sp. and psychrotrophic bacteria in sliced mozzarella cheese as well as to quantify the antimicrobial compound present in the cheese packaging.

\section{MATERIAL AND METHODS}

\section{Production of antimicrobial sachet}

The antimicrobial sachets (PI0603881-6) (21) were produced adding allyl isothiocyanate (AIT) (94 mg.100 mg ${ }^{-1}$ ) to a high absorption polymeric resin (Accurel $^{\circledR}$ XP200, HDPE, Accurel Systems International Corp., Sunnyvale, California, USA). The sachets were prepared with $1 \mathrm{mg} .100$ $\mathrm{mg}^{-1}$ of AIT over the resin weight. After the entire absorption of the AIT by the porous resin, the antimicrobial system was placed in non-tissue sachets, which were hot sealed.

\section{Antimicrobial efficiency of sachet in sliced mozzarella cheese}

Sliced mozzarella cheese was purchased in the local market. Mozzarella slices without preservative were separated by low density polyethylene films (LDPE) and placed in PE/NYLON bags (Cryovac Division, Sealed Air Corporation, Duncan, SC, USA), selected based on its low gas transmission rate. Previous study run by Silva (20) has 
Pires, A.C.S. et al.

shown that the oxygen transmission rate for PE/NYLON films is $2.45 \% \mathrm{O}_{2} / \mathrm{m}^{2} /$ day.

Two antimicrobial sachets were fixed inside these bags with the help of a double-face tape. The packaging materials were sealed and stored at $12{ }^{\circ} \mathrm{C} \pm 2{ }^{\circ} \mathrm{C}$, simulating abusive temperature during transport or storage of the product. The cheese slices were analyzed at $0,3,6,9,12$ and 15 days of storage. Control consisted of packaging without the antimicrobial sachet.

\section{Microbiological analyses}

The cheese slices were submitted to counts of Staphylococcus sp., yeasts and molds and psychrotrophic bacteria in each storage time.

A $25 \mathrm{~g}$ mozzarella slice was aseptically sampled and added to $225 \mathrm{~mL}$ of sodium citrate at $2 \%$. The mixture was homogenized for 1 minute in Stomacher ITR, model 1240. Serial dilutions and aliquots of $0.1 \mathrm{~mL}$ were inoculated onto Baird-Parker agar surface (Difco ${ }^{\circledR}$, Becton, Dickinson and Company, Franklin Lakes, New Jersey, USA), BDA (Difco ${ }^{\circledR}$ ) and PCA (Difco ${ }^{\circledR}$ ), for enumeration of Staphylococcus sp., yeasts and molds and psychrotrophic bacteria, respectively. The plates were incubated at $35^{\circ} \mathrm{C} \pm 2{ }^{\circ} \mathrm{C}$ for $24-48 \mathrm{~h}$ for Staphylococcus sp., at $23{ }^{\circ} \mathrm{C} \pm 2{ }^{\circ} \mathrm{C}$ over 3 to 5 days for yeasts and molds and at $7{ }^{\circ} \mathrm{C} \pm 2{ }^{\circ} \mathrm{C}$ over 7 to 10 days for psychrotrophic bacteria. Plates containing 25 to 250 colonies were selected for counting (1). The results were expressed in UFC.g ${ }^{-1}$.

\section{Quantification of the volatile antimicrobial headspace packaging}

The packaging materials were analyzed at 0,6,9, 12 and 15 days of storage. Aliquots of $100 \mu \mathrm{L}$ of the air contained in the packaging were used for quantification of the antimicrobial compound in a gas chromatograph mass spectrometer (GC-MS).

Analysis was conducted in a Shimadzu chromatograph, model GCMS-QP5050, column DB5 (0.25 mm i.d. x $30 \mathrm{~m}$, $0.25 \mu \mathrm{m}$ thick, Shimadzu Co., Kyoto, Japan). The GC oven temperature increased at $8{ }^{\circ} \mathrm{C} \cdot \mathrm{min}^{-1}$ from $50{ }^{\circ} \mathrm{C}$ to $70{ }^{\circ} \mathrm{C}$, which was maintained for 5 minutes, followed by a new increase from $70{ }^{\circ} \mathrm{C}$ to $78{ }^{\circ} \mathrm{C}$ at a rate of $2{ }^{\circ} \mathrm{C} \cdot \mathrm{min}^{-1}$, which was also maintained for 5 minutes. Finally, there was a new heat increase from $78^{\circ} \mathrm{C}$ to $250{ }^{\circ} \mathrm{C}$ at a rate of $10^{\circ} \mathrm{C} \cdot \mathrm{min}^{-1}$, with the total run time of 38.7 minutes. Helium ( $1 \mathrm{~mL} . \mathrm{min}^{-1}$, split ratio of 1:10) was used as carrier gas.

For AIT quantification, a standard curve with different known concentrations of the antimicrobial was obtained, with a retention time of 7.125 minutes.

\section{Statistical analysis}

The experiment was conducted in three repetitions, arranged in a randomized block design, in a factorial experiment with time and sachet being the factors studied. The decimal logarithms of the microbial counts were submitted to analysis of variance, at $5 \%$ of probability level, and adequately analyzed by the Tukey test, or variance regression, as applied.

For quantification of AIT, the experiment was carried out in three repetitions, in a completely randomized block design. The compound concentrations, expressed in $\mu \mathrm{g} \cdot \mathrm{mL}^{-1}$, were submitted to analysis of variance and analyzed by linear regression.

The statistical analyses were carried out with the help of the program Statistical Analysis System (SAS), version 9.0.

\section{RESULTS AND DISCUSSION}

\section{Antimicrobial efficiency of the sachet in sliced mozzarella cheese}

The initial count of yeasts and molds in the sliced mozzarella was $3.02 \log \mathrm{CFU} \cdot \mathrm{g}^{-1}$. Although the Brazilian legislation has not established limits for these groups of microorganisms in mozzarella, they are frequently involved in the deterioration of cheese, especially sliced cheese. The mold growth causes alterations in the coloration and flavor of the product and there is the possibility of mycotoxin production. 
The antimicrobial sachet was capable of inhibiting $(p<0.05)$ the growth of yeasts and molds throughout storage time (Figure 1). Comparing the counts in the control sample and the antimicrobial-treated sample, a difference of $3.6 \mathrm{log}$ cycles was observed after 15 storage days at $12{ }^{\circ} \mathrm{C} \pm 2{ }^{\circ} \mathrm{C}$. Another study, conducted by Pires et al. (17) achieved a reduction of $2.0 \mathrm{log}$ cycles for yeasts and molds counts in sliced mozzarella. These results show the broad antimicrobial effect of AIT against this group of microorganisms.

The initial counts of Staphylococcus sp. were high (4.45 CFU.g $\left.{ }^{-1}\right)$. The colonies were Gram-positive but typical coagulase-positive Staphylococcus sp. were not found, what meets the Brazilian legislations, which proposes standards only for coagulase-positive Staphylococcus sp.. However, studies have shown that coagulase-negative Staphylococcus sp. can be involved in food poisoning outbreaks. Research carried out by Vernozy-Rozand et al. (22) verified that $5.3 \%$ of the 187 coagulase-negative Staphylococcus sp. strains isolated from goat's milk and cheese produced enterotoxin. Pools of coagulase-negative Staphylococcus sp. isolated from Canastra cheese samples were positive for production of enterotoxin B, C and D, and TSST-1 toxin (2). Carmo et al. (3) also showed the presence of these microorganisms in milk responsible for food poisoning outbreak in Minas Gerais, Brazil.

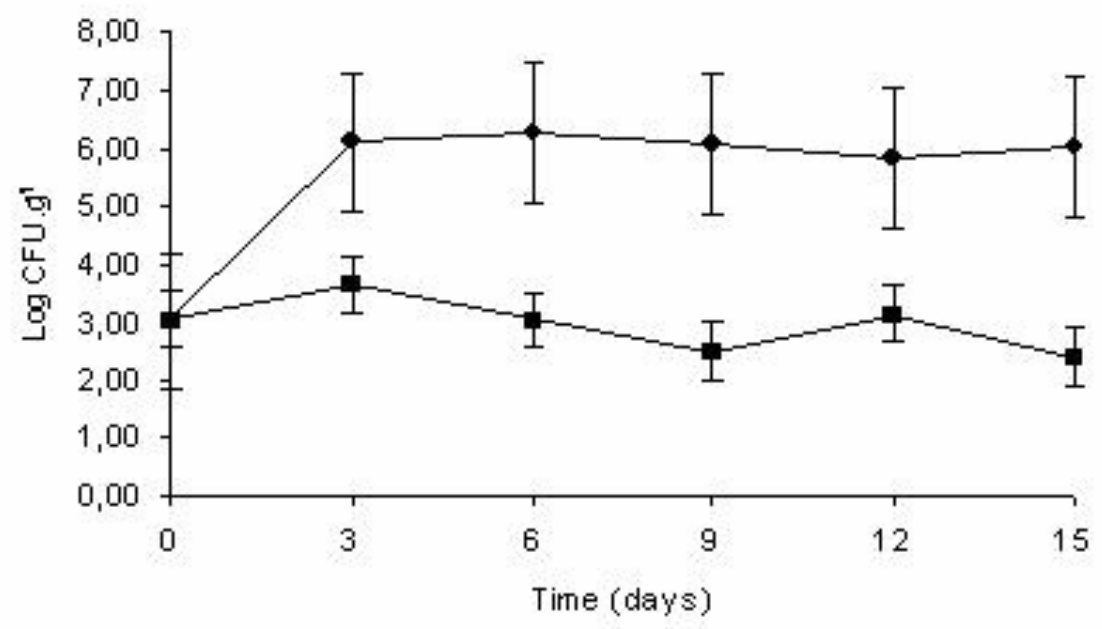

Figure 1. Effect of the antimicrobial sachet on the growth of yeasts and mold in sliced mozzarella cheese: (•) Packaging without sachet (匹) Packaging with antimicrobial sachets.

Up to the three days of storage, Staphylococcus sp. counts in treated and non-treated samples presented no difference ( $\mathrm{p} \geq 0.05$ ) (Figure 2). From the 6-day until the 12day of storage, the count of these microorganisms in the packaged samples containing sachets was lower $(\mathrm{p}<0.05)$ than in the control sample, indicating their efficiency against Staphylococcus sp. On the 9-day, the difference in counts in the treated and non-treated samples was $4 \log$ cycles. At the end of the storage time (15 days), means of the treated and non-treated samples did not differ $(p \geq 0.05)$. However, the counts at the end of the storage time (15 days) did not differ significantly in the two types of samples.

The initial psychrotrophic bacteria count was $4.64 \log$ CFU.g ${ }^{-1}$. This group of microorganisms causes several problems in the dairy industry due to production of heat resistant proteases and lipases which alter the texture, flavor, and yield of the cheese. At 9 and 15 days of storage, a significant difference $(\mathrm{p}<0.05)$ in counts of psychrotrophic bacteria in treated and the non treated samples was observed (Figure 3). On the $9^{\text {th }}$ day of storage, this difference reached 
Pires, A.C.S. et al.

$1.7 \log$ cycles; however, on the $15^{\text {th }}$ day, the difference was less than a $1 \log$ cycle.

It was also observed that when the antimicrobial treatedcheese samples were plated out, the colonies formed on the different media used for enumeration were smaller than those originated from the non-treated samples, indicating that the volatile antimicrobial may have caused injury to the cells. Similar results were also observed by Lin et al. (11).

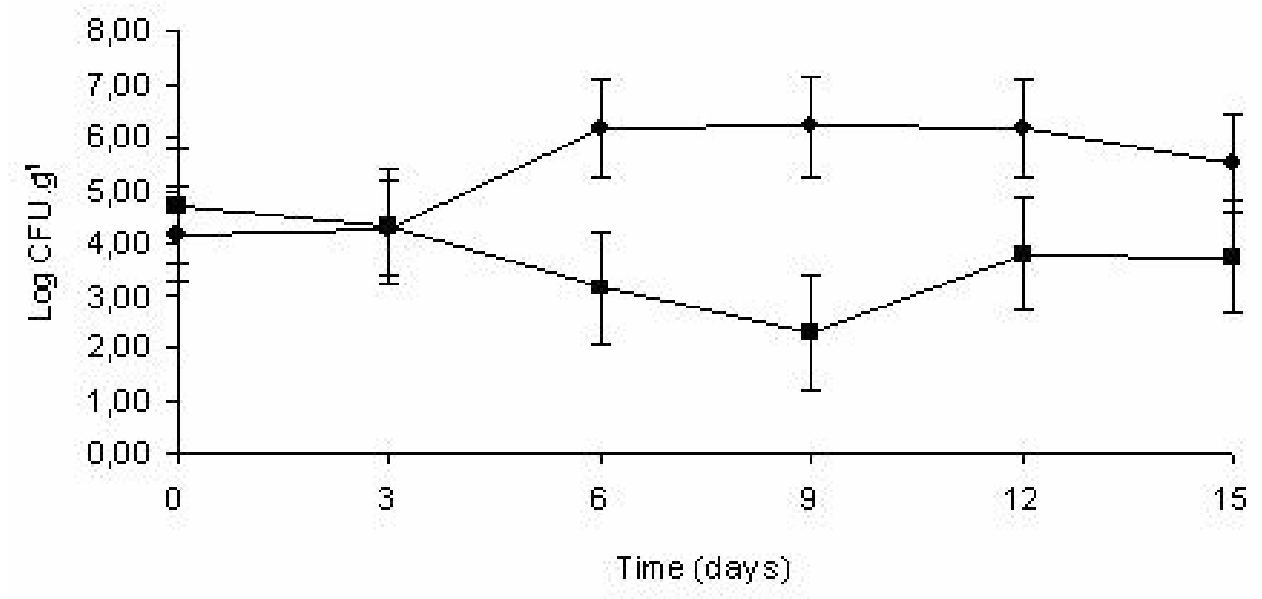

Figure 2. Effect of antimicrobial sachet on the growth of Staphylococcus sp. in sliced mozzarella cheese: (•) Packaging without sachet (घ) Packaging with antimicrobial sachet.

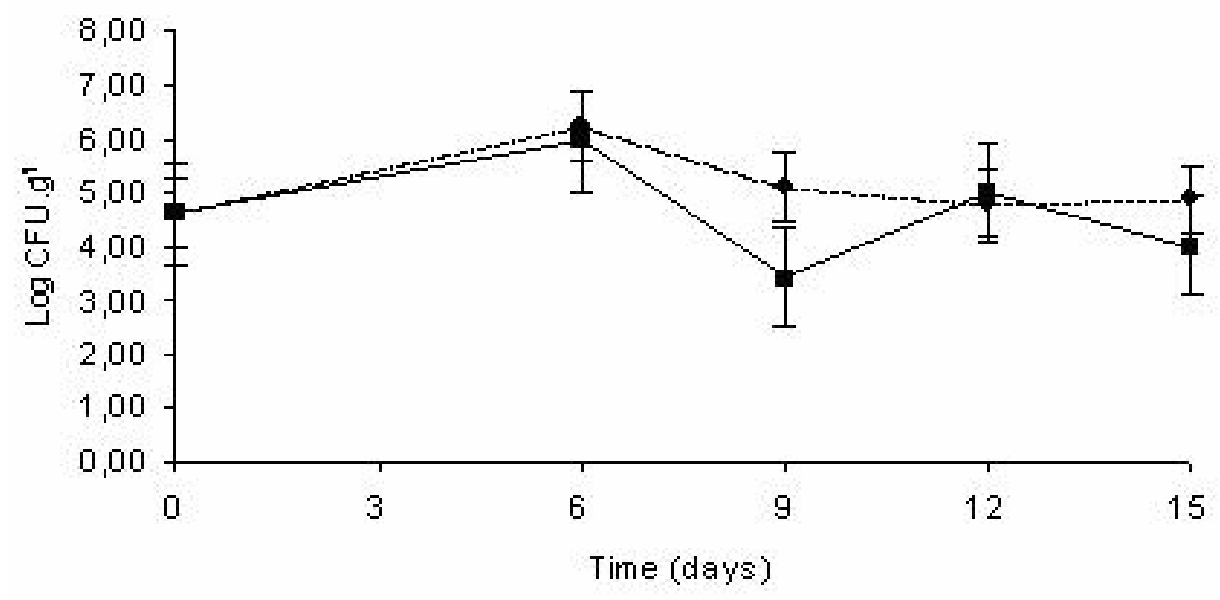

Figure 3. Effect of the antimicrobial sachet on the growth of psychrotrophic bacteria in sliced mozzarella cheese: Packaging without sachet (ロ) Packaging with antimicrobial sachet.

\section{Quantification of the volatile antimicrobial in the free} space of the packaging

The amount of volatile antimicrobial present in the packaging headspace varied significantly $(p<0.05)$ along the storage (Figure 4). Based on the amount of antimicrobial incorporated into the resin and on the amount that volatized into packaging headspace, the theoretical antimicrobial concentration was calculated to be $3.26 \mu \mathrm{g} \cdot \mathrm{mL}^{-1}$. After 6 days 
of storage, the maximum antimicrobial amount was reduced to $0.08 \mu \mathrm{g} \cdot \mathrm{mL}^{-1}$ and decreased to only $0.02 \mu \mathrm{g} \cdot \mathrm{mL}^{-1}$ on the $15^{\text {th }}$ day of storage at $12^{\circ} \mathrm{C} \pm 2^{\circ} \mathrm{C}$, probably due to the antimicrobial interaction with lipids $(7,12,13)$ and groups such as thiols, sulphydryls, free amino acids, and protein disulphides (8). Reduced volatile antimicrobial concentration may also have occurred due to antimicrobial interaction with the resin, as well as its adsorption and permeation through the packaging material (10). Nadarajah et al. (12) added $0.5 \mathrm{~mL}$ and $1.0 \mathrm{~mL}$ corn oil containing $70 \%$ of volatile antimicrobial of plant origin in filter paper into an active packaging system for ground beef and observed that after two days of storage at $10^{\circ} \mathrm{C}, 95 \%$ of the initial concentration of $1.33 \mu \mathrm{g} \cdot \mathrm{mL}^{-1}$ was maintained.

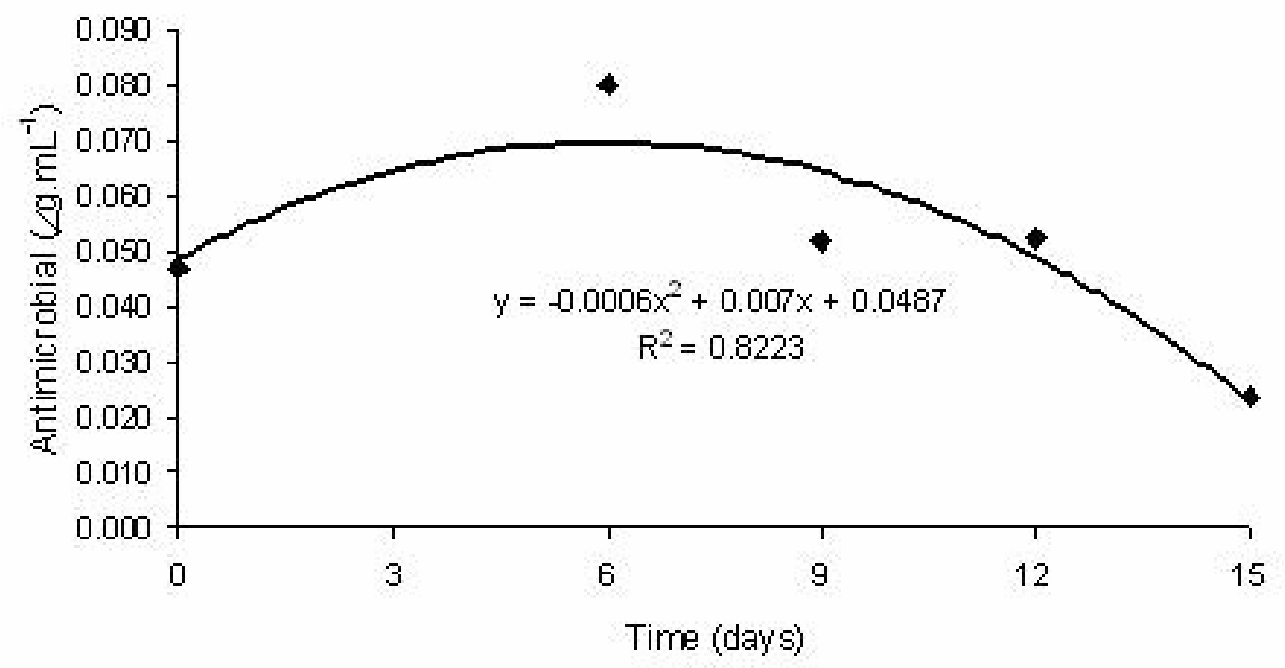

Figure 4. Concentration of allyl isothiocyanate inside the packaging during the mozzarella cheese storage period.

In conclusion, the active packaging system containing allyl isothiocyanate has a great potential to be applied in cheese for inhibition of the growth of deteriorating and potentially pathogenic microorganisms, such as Staphylococcus sp., frequently involved in poisoning outbreaks.

\section{ACKNOWLEDGEMENTS}

The authors are grateful to CAPES, CNPq, FAPEMIG and FINEP for financial support.

\section{REFERENCES}

1. APHA - American Public Health Association. (2001). Compendium of Methods for the Microbiological Examination of Foods, 4th ed. American Public Health Association, Washington, DC, USA.
2. Borelli, B.M.; Ferreira, E.G.; Lacerda, I.C.A.; Santos, D.A.; Carmo, L.S.; Dias, R.S.; Silva, M.C.C.; Rosa, C.A. (2006). Enterotoxigenic Staphylococcus spp. and other microbial contaminants during production of Canastra cheese, Brazil. Braz. J. Microbiol, 37 (4), 545550.

3. Carmo, L.S.; Dias, R.S.; Linardi, V.R.; Sena, M.J.; Santos, D.A.; Faria, M.E.; Pena, E.C.; Jett, M.; Heneine, L.G. (2002). Food poisoning due to enterotoxigenic strains of Staphylococcus present in Minas cheese and raw milk in Brazil. Food Microbiol. 19 (1), 9-14.

4. Chacon, P.A.; Buffo, R.A.; Holley, R. A. (2006). Inhibitory effects of microencapsulated allyl isothiocyanate (AIT) against Escherichia coli O157:H7 in refrigerated, nitrogen packed, finely chopped beef. Int. J. Food Microbiol., 107(3), 231 - 237.

5. Delaquis, P.J.; Ward, S.M.; Holley, R.A.; Cliff, M.C.; Mazza, G. (1999). Microbiological, chemical and sensory properties of pre-cooked roast beef preserved with horseradish essential oil. J.Food Sci. 64 (3), 519-524.

6. Han, J.H. (2003). Antimicrobial Food Packaging. In: Ahvenainen, R. (ed.) Novel Food Packaging Techniques. CRC Press, Washington, 
Pires, A.C.S. et al.

USA, p. 50-65.

7. Isshiki, K.; Tokuoka, K.; Mori, R.; Chiba, S. (1992). Preliminary examination of allyl isothiocyanate vapor for food preservation. Bios.Biotechnol.Bioch. 56 (9), 1476-1477.

8. Kim, Y.S.; Ahn, E.S.; Shin, D.H. (2002). Extension of shelf life by treatment with allyl isothiocyanate in combination with acetic acid on cooked rice. J.Food Sci. 67 (1), 274-279.

9. Legnani, P.; Leoni, E.; Berveglieri, M.; Mirolo, G.; Alvaro, N. (2004). Hygienic control of mass catering establishments, microbiological monitoring of food and equipment. F. Control 15 (3), 205-211.

10. Lim, L.T.; Tung, M.A. (1997). Vapor pressure of allyl-isothiocyanate and its transport in PVDC/PVC copolymer packaging film. J.Food Sci. 62 (5), 1061-1067.

11. Lin, C.M.; Preston, J.F.; Wei, C. (2000). Antibacterial mechanism of allyl isothiocyanate. J.Food Prot. 63 (6), 727-734.

12. Nadarajah, D.; Han, J.H.; Holley, R.A. (2005). Inactivation of Escherichia coli O157:H7 in package ground beef by allyl isothiocyanate. Int.J.Food Microbiol. 99 (3), 269-279.

13. Nadarajah, D.; Han, J.H.; Holley, R.A. (2005). Use of mustard flour to inactivate Escherichia coli O157:H7 in ground beef under nitrogen flushed packaging. Int.J.Food Microbiol 99 (3), 257-267.

14. Nguyen, V.T.; Gidley, M.J.; Dykesc, G.A. (2008). Potential of a nisincontaining bacterial cellulose film to inhibit Listeria monocytogenes on processed meats. Food Microbiol., 25(3), 471-478.

15. Nielsen, P.V.; Rios, R. (2000). Inhibition of fungal growth on bread by volatile components from spices and herbs, and the possible application in active packaging, with special emphasis on mustard essential oil.
Int.J.Food Microbiol 60 (2-3), 219-229.

16. Nychas, G.J.E.; Skandamis, P.N. (2003). Antimicrobials from herbs and spices. In: Roller, S. (Ed.) Natural Antimicrobials for the Minimal Processing of Foods, Woodhead Publishing Limited, Cambridge, England, p.177-201.

17. Pires, A.C.S.; Soares, N.F.F.; Andrade, N.J.; Silva, L.H.M.; Camilloto, G.P.; Bernardes, P.C. (2008). Development and evaluation of active packaging for sliced Mozzarella preservation. Packag. Technol. Sci., 21(7), 375-383.

18. Roller, S. (2003). Introduction. In: Roller, S. (ed.) Natural Antimicrobials for the Minimal Processing of Foods, Woodhead Publishing Limited, Cambridge, England, p. 1-10.

19. Santiago-Silva, P.; Soares, N.F.S.; Nobrega, J.E.; Junior, M.A.W.; Barbosa, K.B.F.; Volp, A.C.P.; Zerdas, E.R.M.A.; Wurlitzer, N.J. (2009). Antimicrobial efficiency of film incorporated with pediocin (ALTA_2351) on preservation of sliced ham. F. Control, 20(1), 85-89.

20. Silva, W.A. (2008). Desenvolvimento e avaliação de embalagens ativas para a melhoria da segurança alimentar de amendoim (Arachis hipogaea L.). Viçosa, Brasil, 64p. (D.Sc. Thesis. Departamento de Tecnologia de Alimentos. UFV).

21. Soares, N.F.F.; Pires, A.C.S.; Camilloto, G.P. (2008). Sachê antimicrobiano para uso em alimentos. Revista da Propriedade Intelectual, 1946, 70-71.

22. Vernozy-Rozand, C.; Mazuya, C.; Prevosth, G.; Lapeyrec, C.; Besd, M.; Brund, Y.; Fleuretted, J. (1996). Enterotoxin production by coagulase-negative Staphylococci isolated from goat's milk and cheese. Int.J.Food Microbiol 30 (3), 271-280. 